\title{
The advantages of using a Geographic Information System to evaluate risk in highly contaminated sites
}

\author{
S. Bellagamba, F. Paglietti \& B. C. D. Staffa \\ INAIL-DIPIA Department of Production Pants and \\ Anthropic Settlements, Italy
}

\begin{abstract}
Italian Workers' Compensation Authority (INAIL), in collaboration with local and national organisations, conducts research and consultancy in connection with the safeguarding of the health of workers and the environment. The Department of the Production Plants and Human Settlements (DIPIA) deals, among other things, with the remediation of seriously contaminate areas, and for many years has undertaken the survey of the atmospheric, water and soil environments, and in particular environmental and personal monitoring in all the Italian Superfunds contaminated by asbestos and requiring remediation.

The aim of this study is to illustrate, with regard to the Superfund Biancavilla, the advantages of implementing the activities mentioned above with a Geographic Information System (GIS) designed to provide an adequate picture of the risk of the spread of asbestos fibres in the areas where Emergency Safety Measures (ESM) and remediation measures are planned.

This will enable the regional and local authorities and the supervisory bodies having jurisdiction to undertake precautionary measures regarding the workers involved in these projects and prevent the dissemination of dangerous dust in the urban environment.
\end{abstract}

Keywords: asbestos, Geographic Information System, risk, superfund.

\section{Introduction}

In accordance with Ministerial Decree 468/01 and subsequent amendments and additions, one of the best known Italian Superfunds requiring treatment is the town of Biancavilla (Catania), an urban area with a population of approximately 
24.000 on the slopes of Mount Etna; here, the natural environment contains a fibrous volcanic amphibole called "fluoro-edenite", known to be a potential cancer agent. Since two quarries have operated in the area for over 30 years to take the material with which most of the town has been built, there is still environmental pollution.

The dangerous character of these pollutant fibres has been shown to be the same as crocidolite, the most dangerous asbestos minerals; quarrying has thus been stopped in this area and emergency safety measures implemented to reduce the dispersion of dangerous dust.

Measures have likewise been initiated to reduce the amount of dust in the town area, which is also polluted by fluoro-edenite fibres in the soil. A site in the quarry area has been identified to deposit the materials collected in the ESM measures.

For some years, INAIL-DIPIA has participated activities for the profiling of environmental systems, and in particular for atmospheric monitoring throughout the site, in order to assess la variability in the concentration of dangerous dust in relation to the seasons, rainfall conditions and remediation measures implemented.

The aim of this study is to illustrate the advantages accruing from the implementation of the above-mentioned activities with GIS that can effectively show the risk of dissemination of "fluoro-edenite" ain the urban area during the following phases:

- pre-works;

- during-works;

- post-works.

\section{Survey of the site of Biancavilla}

In Biancavilla (Catania), a town with a population of 24.000 on the slopes of Mount Etna, over the past 20 years approximately 40 deaths have been recorded due to pleural mesothelioma, an asbestos-related disease; the rate is 10 times higher than the national average.

The pollutant is fluoro-edenite, a bright yellow fibrous mineral consisting of numerous small fibres (in some cases with a diameter of 1 micron) and relatively long (up to 50-80 micron).

It has been detected in hundreds of analyses and core samples and in thousands of monitoring results for air-borne particles to assess the extent of the contamination and to determine the concentration rate of these fibres in the air. It has also been detected in the water, but with a concentration under the risk threshold.

The analyses made have shown that a large number of samples taken were in some cases higher than the levels allowed.

Since 2001, the Ministry of the Environment and the Protection of the Territory and the Sea has, with the technical and scientific support of national scientific agencies including INAIL-DIPIA, managed the procedures for emergency safety and remediation measures. 
The phase for ensuring safety, currently being implemented in the town of Biancavilla, mainly regard measures designed to reduce the dispersion of fibres and the contamination of the risk area.

These operations started with the paving of the town streets, after the completion of the power supply and sewer system in 2010, and continued in 2011 with the following activities:

- channelling of rainwater and covering of piles of contaminated material already quarried with a layer of fill, regarding the Emergency Safety Measures implemented in the quarry;

- daily covering of contaminated material in the waste tip installed in the quarry area with a layer of fill;

- application of fibre-reinforced cement (spray cement) for the consolidation of the rock wall in the quarry area;

- removal plastering and application encapsulating applications in public buildings with a large number of persons subject to risk such as:

- the perimeter area of the municipal cemetery;

- an infant school;

- the sports centre;

- the conference centre owned by the municipality.

This study presents the results of analysis of the aforesaid emergency measure monitoring, assessment of population exposure risk with Geographic Information System (GIS) instruments and verification of the effectiveness of dust reduction measures during operational activities.

\section{Materials and methods}

From 2000 to 2012, 260 environmental sampling points have been identified at the site, and over 1.900 samples of air-borne particles have been taken for the environmental and personal monitoring. This sampling has been conducted by INAIL- DIPIA, the University of Catania, Regional Agency for Environmental Protection (ARPA Sicily), private laboratories commissioned by the municipal authorities and Circum-Etna Railway.

The data acquired has been stored and managed by INAIL- DIPIA thanks to a dedicated local GIS and regard:

- Date of sampling;

- Place of sampling;

- Volume of sample;

- Weather conditions;

- Analysis methodology;

- Concentration value recorded in $\mathrm{f} / \mathrm{l}$;

- Lower and upper threshold levels;

- Analytical methodologies (SEM or MOCF).

The samples for both personal and environmental monitoring (indoor and outdoor) were collected according to the guidelines written by INAIL-DIPIA for remediation measures in superfund. 
A computer database associated with a GIS is the indispensable tool for managing such a large amount of data a large number of samplings. The database is designed for the collection, organisation, la management, updating and easy consultation of, while the GIS allows their insertion in the territorial, i.e. geographical context.

This GIS may be accessed by query, and thus describe the development over time of facts regarding pollution/remediation and to highlight risky situations.

The GIS is characterised by the topological structuring of data (management of information on mutual spatial relationships of the elements), the option of analysing the attributes and the possibility of processing geographical data through mathematical algorithms. Using algorithms, we can combine the various information levels using simple tools such as overlay or complex tools like buffering which enable us to create new information levels by associating the data in such a way as to identify relationships which are not otherwise easily detectable.

The software used for the management of the mapping database is ArcGis 10 by Esri, while Access software by Microsoft has been used for the alphanumerical database.

In the specific case of the Municipality of Biancavilla, the results of sampling were recorded in a specific database; interrelated tables were then created; two specific display formats were then created, one for filing the environmental samples (Figure 1), and one for the personal samples (Figure 2), to facilitate data entry.

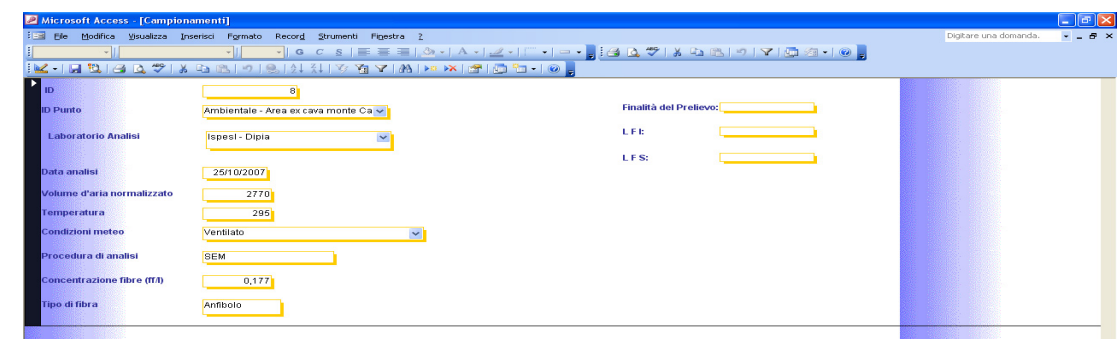

Figure 1: Display format for information on environmental samples.

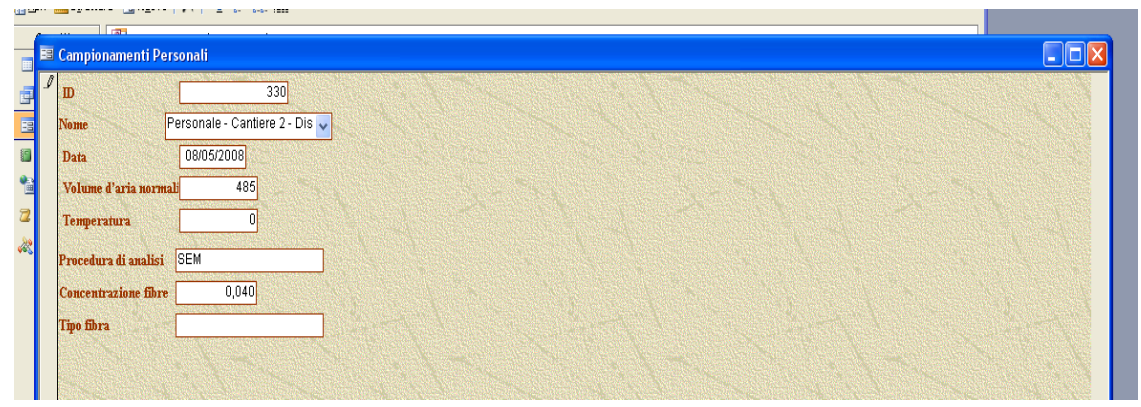

Figure 2: Display format for information on personal samples. 
For sake of completeness, we can point out that the database contains 380 records referring to 37 persons subjected to personal monitoring in the period 2008-2010, the time period for which the measurements were standardised.

Geo-referenced shapefiles were also inserted in the GIS with the following vector layers:

- $\quad$ sampling points;

- $\quad$ municipal grid;

- $\quad$ provincial grid;

- $\quad$ regional grid;

- $\quad$ road and railway grid derived from the Teleatlas graph;

- $\quad$ population density map obtained with ISTAT data on the population census (2001);

- $\quad$ Sensitive receptors (schools, hospitals etc.).

Geo-referenced layers were also included in raster format such as:

- IKONOS high resolution satellite images;

- orthophotograph.

In order to be inserted in the GIS, the layers have been geo-referenced in the WGS84 UTM 32 mapping reference system.

The system enables users to query the alphanumerical database and display on the map the analysis values obtained from the samples, thus providing mapping of the various levels of exposure.

Figure 3 shows the points were environmental sampling was conducted.

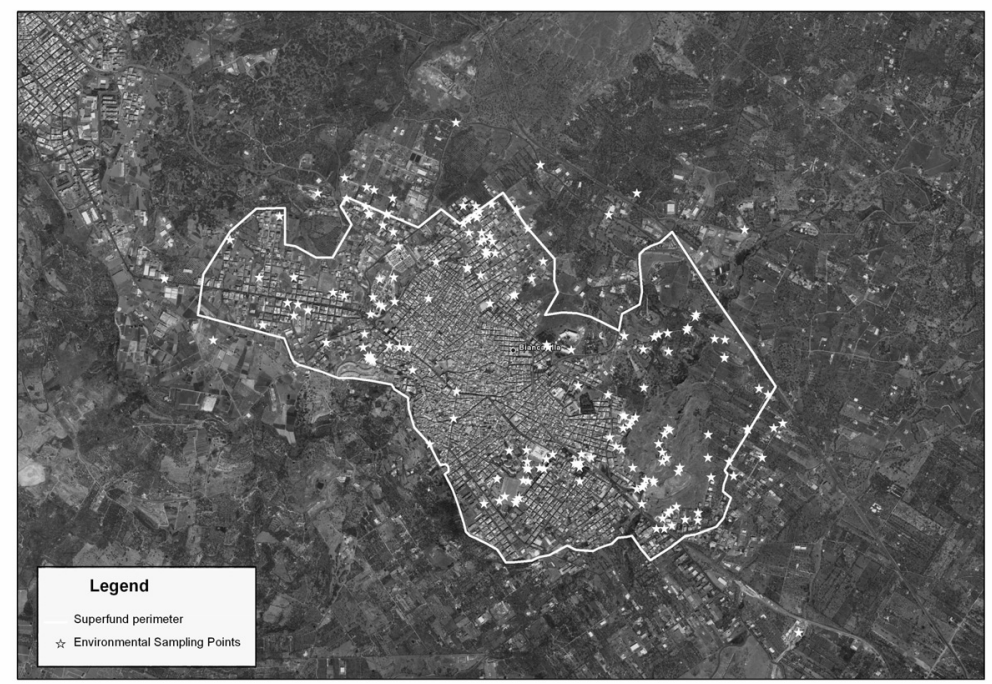

Figure 3: Location of environmental sampling points in the Biancavilla. 


\section{Discussion}

Analytical data on environmental monitoring, produced from 2010 to March 2012 in the town of Biancavilla, inside and outside the superfund, was extracted from the GIS and analysed. The results of monitoring conducted in the preworks, during-works and post-works stages of the measures implemented at the working sites were likewise analysed (Figure 4).

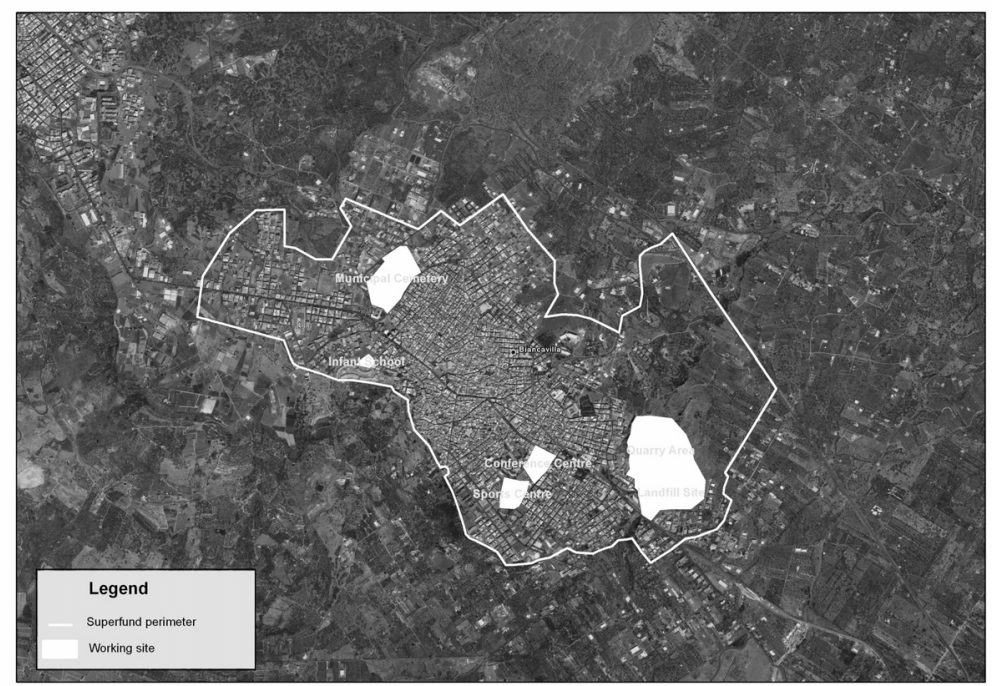

Figure 4: $\quad$ Areas for emergency safety measures.

As for the environmental samples, analysis was conducted on data from samples in which the maximum exposure limit stated for the superfund, i.e. $1 \mathrm{f} / 1$ in an urban environment, as set forth in the document Air Quality Guidelines for Europe (WHO, 2000).

The processing of the data and their graphic display (Figure 5) show 26 episodes in which levels were exceeded in the period March 2010 - 2012.

In particular, in 2010 there were 21 samples in which the Threshold Limit Value (TLV) was exceeded in the spring/summer period, characterised by concentrations of fibres under $2 \mathrm{f} / \mathrm{l}$. In 2011, on the other hand, in the same period (spring/summer) there were 5 samples with values exceeding $3 \mathrm{f} / \mathrm{l}$.

This shows a constant increase in the risk during the dry weather. This corresponds to ascertained weather data showing that in the warmer seasons the conditions facilitate the dispersion of air-borne fibres (strong winds and dry climate).

In both years, many of the excess level samples were recorded in the northern area of the site, outside the perimeter of the superfund, since in this area all the roads had not been paved. Further data processing regarded the analysis of monitoring results and the operational phases of the ESM work. 


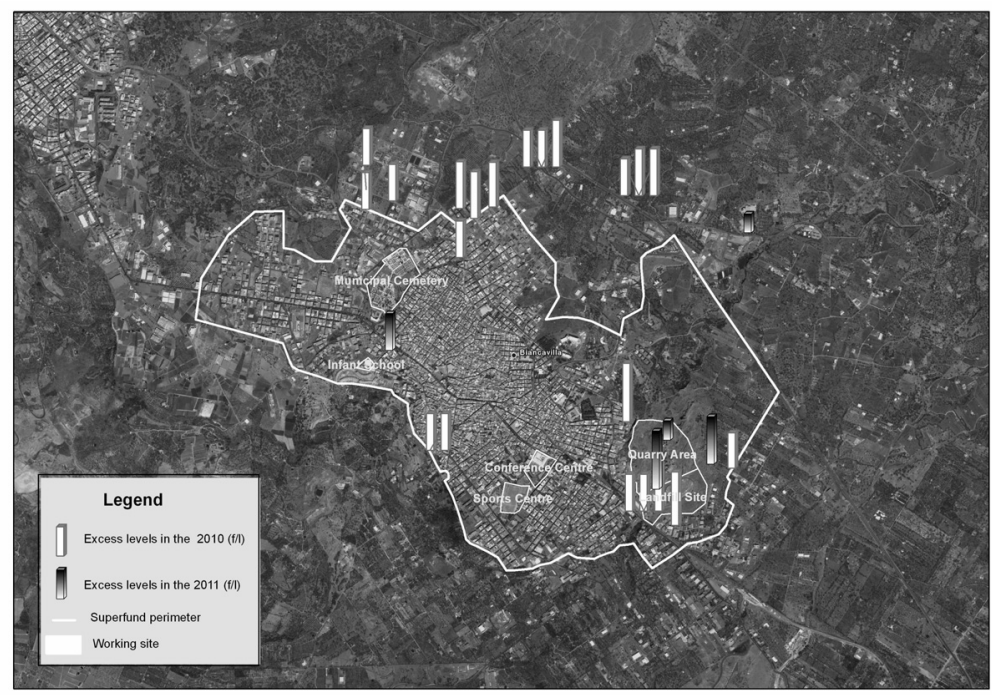

Figure 5: $\quad$ Map of excess levels in the 2-year period 2010-2011 in the town of Biancavilla.

Table 1 shows the percentage values calculated on the total number of environmental analyses conducted in the area during the three operational phases (2010-2011).

Table 1: $\quad$ Environmental analyses conducted.

\begin{tabular}{|l|c|}
\hline \multicolumn{1}{|c|}{ Phase } & $\begin{array}{c}\text { Environmental analyses } \\
\text { conducted } \\
(\mathbf{\%})\end{array}$ \\
\hline Pre-works & 17 \\
\hline During-works & 52 \\
\hline Post-works & 31 \\
\hline
\end{tabular}

The purpose of the environmental analyses conducted in the Pre-works stage was to verify the degree of contamination of the site and to establish the background environmental value. The analyses conducted during the works phase, on the other hand, serve to verify environmental safety during the ESM.

Finally, in the post-works phase, the environmental analyses are conducted in order to check that the level of values recorded in the pre-works phase, and the threshold level set for the site. The percentage value during the works phase is obviously much higher than in the other two phases.

This is due to the greater risk of fibre dispersion due to the work under way. The diagram in Figure 6 shows the concentrations higher than $0 \mathrm{f} / \mathrm{l}$ on 21 analyses conducted before starting the work activity in the areas where the 


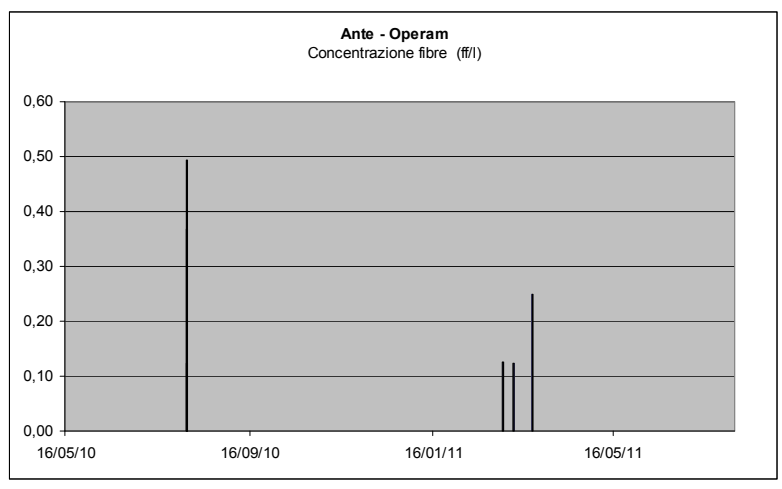

Figure 6: Graph of pre-works concentrations.

measures were conducted; in these areas, the fibre concentration level considered to be the background value is between 0 and $0.5 \mathrm{f} / 1$.

During the execution of works, on 70 analyses conducted, the episodes in which the values of the threshold for the superfund were exceeded showed a value of $1 \mathrm{f} / \mathrm{l}$ with peaks sometimes exceeding $3 \mathrm{f} / \mathrm{l}$ (Figure 7). These concentrations are due to the removal of soil and of piles of quarried material contaminated by fluoro-edenite still present in the quarry, although procedure to contain the dissemination of dust had been implemented (spraying, fog cannon etc.).

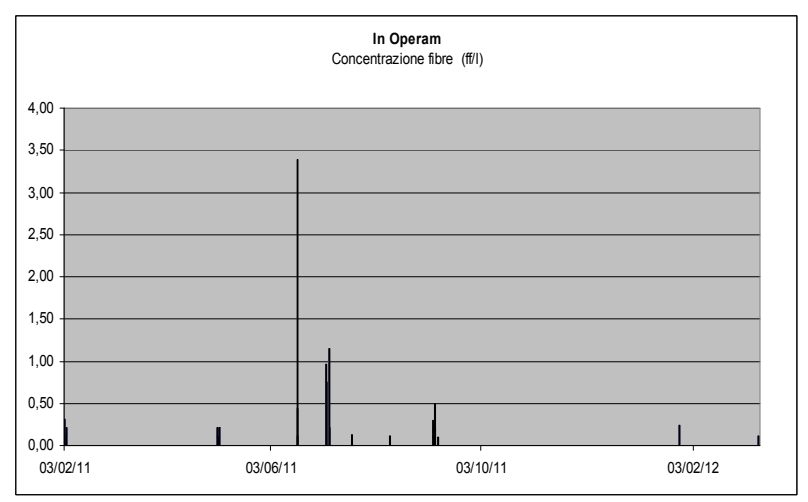

Figure 7: Graph of during-works concentrations.

The values observed in the post-works phase on 40 analyses conducted are under the threshold limit in most worksite areas. The exception is in the quarry area, where levels were exceeded due to the collateral activity still under way at the site and the waste tip (covering of contaminated soil with inert fill, spray cement application of sloping surfaces etc.), and there is still a significant dust dispersion (Figure 8). 


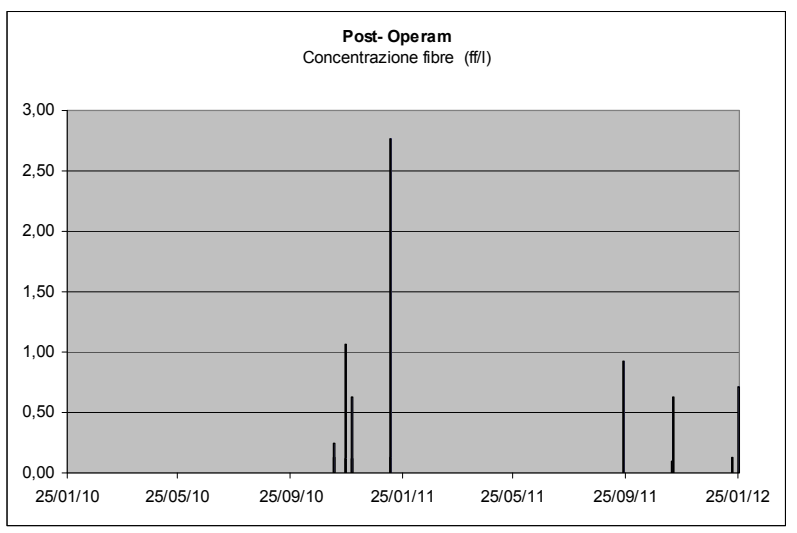

Figure 8: Graph of post-works concentrations.

From the analysis of all the results of environmental sampling conducted in the town of Biancavilla from 2000 to 2011, we can see a significant fall in the concentration of fibres in the first years (blocking of activity in the quarry and paving of roads) and a subsequent stabilisation, though with some exceptions in special cases (excavations for public works, water supply and sewer system).

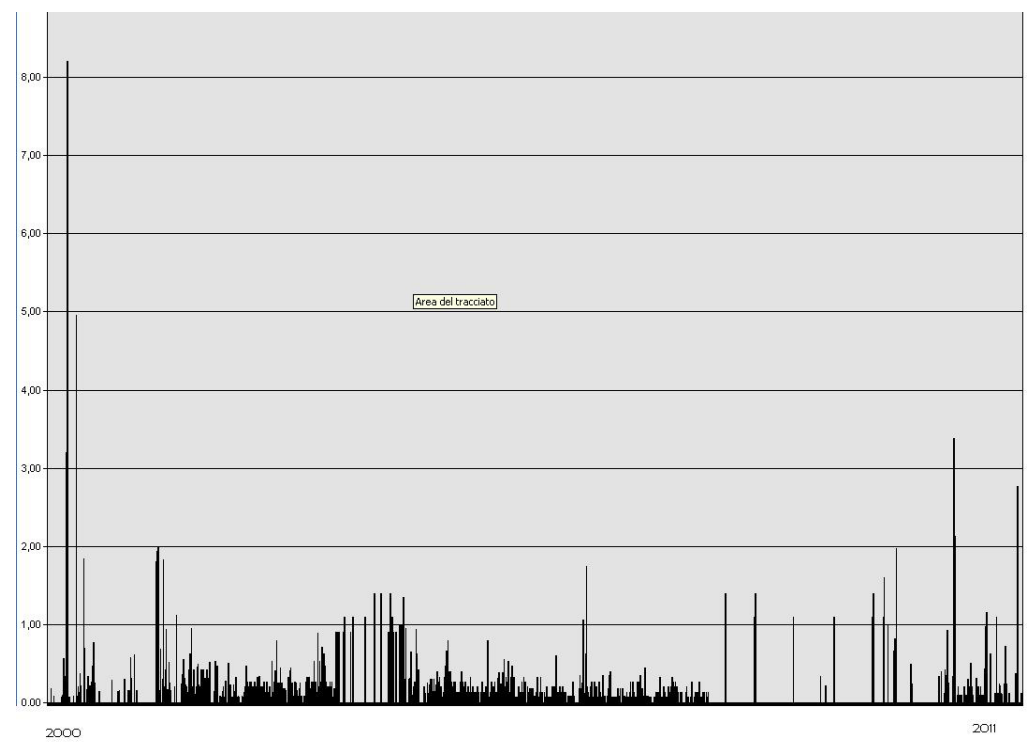

Figure 9: Results of sampling conducted in the town of Biancavilla (2000-2011).

In recent years, as shown in Figure 9, there has been a significant increase in concentrations in some cases due to ESM works. 
These increases were detected not only in the quarry area, where most of the work for shifting contaminated material took place, but also had repercussions over the entire urban area. This is due to the climatic conditions favouring the dispersion of air-borne fibres and their transport, often for considerable distances.

\section{Conclusions}

The field trials have shown the advantages of using GIS technology as a valid instrument for the correct cataloguing of large amounts of data and the highlighting of situations involving the greatest environmental risks in order to support precautionary decisions to be adopted.

It has also allowed for easy consultation of data by the authorities with jurisdiction for conducting the works, as well as for the population exposed, thanks to automatic implementation and analysis procedures.

The Local Information System specially produced for the town of Biancavilla may thus be considered as a valid reference system for monitoring and verifying remediation measures for the contaminated areas.

The results obtained have also shown the following:

- the environmental contamination of the areas no longer corresponds to the superfund perimeters published in Italian Official Journal $\mathrm{N}^{\circ} 231$ of 2 October 2002 since the contamination also occurs in the urban areas to the north of the town centre;

- the fact that in some cases the limits set by the superfund have been exceeded is due to weather conditions favouring the dispersion of airborne fibres, together with insufficient systems adopted by the firms for reducing dust levels during their work at the site;

- the need to improve the classification of the various worksite operational phases, considering the post-works phase to be the one in which work is not conducted.

\section{References}

[1] S. Bellagamba, F. Paglietti, V. Di Molfetta, F. Damiani and P. De Simone "GIS for data management of environmental surveys, carried out in Biancavilla (CT) superfund experience." Wessex Institute of Technology 19th International Conference on Air Pollution 2011 19-21 September 2011.

[2] F. Paglietti, V. Di Molfetta, S. Malinconico, M. Giangrasso, S. Bellagamba, F. Damiani. Italian Asbestos Mapping. World Asbestos Conference October 1-3 2009.

[3] F. Paglietti, S. Bellagamba, S. Malinconico, V. Di Molfetta, P. De Simone, M. Giangrasso "Asbestos presence on the Italian National Territory: Progress Report on Mapping and Remediation Activity" ASTM Johnson Conference: Critical Issues in Monitoring Asbestos, (Vermont, USA), 2008. 
[4] F. Paglietti, S. Malinconico, F. Damiani, P. De Simone - "Natural Asbestos Contamination: Biancavilla's Case" - ASTM 2008 Johnson Conference: Critical Issues in Monitoring Asbestos, (Vermont, USA).

[5] A. Gianfagna, R. Oberti "Fluoro-edenite from Biancavilla (Catania, Sicily, Italy): crystal chemistry of a new amphibole end-member", (2001). American Mineralogist. vol. 86, pp. 1489-1493.

[6] F. Paglietti, S. Malinconico, F. Damiani, P. De Simone "Natural Asbestos Contamination: Biancavilla's Case" - ASTM 2008 Johnson Conference: Critical Issues in Monitoring Asbestos, (Vermont, USA).

[7] M. Soffritti, F. Minardi, L. Bua, D. Degli Esposti, F. Belpoggi - "First experimental evidence of peritoneal and pleural mesotheliomas induced by fluoro-edenite fibres present in Etnean volcanic material from Biancavilla (Sicily, Italy)”. Eur J Oncol 2004, 9:169-175. 